\title{
RESEARCH ACTIVITIES OF EPIDEMIOLOGY IN JAPAN
}

\section{Epidemiology of Diseases of Unknown Etiology, Specified as "Intractable Diseases"}

\author{
Yoshiyuki Ohno', Takashi Kawamura', Akiko Tamakoshi', Kenji Wakai', Rie Aoki', Masayo \\ Kojima', Yingsong Lin', Tsutomu Hashimoto², Masaki Nagai', and Masumi Minowa ${ }^{4}$
}

\begin{abstract}
In Japan, epidemiological studies on intractable diseases have been undertaken and greatly promoted for more than 20 years by the Research Committee on Epidemiology of Intractable Diseases, with the financial supports from the Ministry of Health and Welfare of Japan. In this paper, chronological history of development of the Research Committee and some scientific accomplishments by the recent Research Committee (1993-1995) were summarized, mainly focusing on descriptive, analytical and other epidemiological studies. Hoped is that the readers are to be acquainted with the recent research activities by the Research Committee and seek for possible international collaborations in epidemiological studies on intractable diseases. J Epidemiol, 1996 ; 6 : S87-S94.
\end{abstract}

epidemiology, intractable diseases, Japan, estimated annual number of patients treated and subsidized

So-called intractable diseases are arbitrarily definable and, therefore, numerous in number. In 1971, however, the Ministry of Health and Welfare of Japan defined them as such diseases of unknown etiology, those with no established treatment regimens and with very high probability of severe sequelae of physical, mental and social difficulties, and those also characterized by chronic disease processes and by large economic and psychological burdens to the patients and their family members as well. Even by this definition, intractable diseases are still numerous in number, and then, the Ministry excluded such intractable diseases that could be readily covered by the currently existing administrative policies, and named the remaining as "Specified Intractable Diseases".

Based on this definition, the Ministry has financially supported scientific researches on many intractable diseases by organizing "Research Committees on Specific Intractable Diseases", and provided partial subsidies of medical costs to the patients treated for specified intractable diseases since 1972. These governmental policies have also been supplementarily strengthened by promoting community-based health services for the patients and by making adequate arrangements for treatment in selected medical institutions throughout Japan.
Because of these governmental policies, a substantial number of scientific researches have been dramatically promoted for many diseases of unknown etiology over 20 years, including epidemiological investigations.

In this communication, the authors will describe the chronological development of the Research Committee on Epidemiology of Intractable Diseases, and exemplify the research activities with some important scientific outcomes in the recent three fiscal years of 1993-1995.

\section{HISTORY OF THE RESEARCH COMMITTEE ON EPIDEMIOLOGY OF INTRACTABLE DISEASES}

Around 1967-1968, an epidemic of SMON (Subacute Myelo-Optico-Neuropathy), which had been known as a neurological disease of unknown etiology since circa 1965, was suddenly observed on nation-wide scale in Japan. Then, the Ministry of Health and Welfare of Japan took the initiative in organizing the scientific research committee on SMON. The sociomedical background behind this decision later prompted the Ministry to organize with due financial supports many

\footnotetext{
Received and accepted March 9, 1996.

${ }^{1}$ Department of Preventive Medicine, Nagoya University School of Medicine, Nagoya, Japan.

${ }^{2}$ Department of Public Health, Wakayama Medical College, Wakayama, Japan.

${ }^{3}$ Department of Public Health, Saitama Medical School, Saitama, Japan.

${ }^{4}$ Department of Epidemiology, The Institute of Public Health, Tokyo, Japan.

Address for correspondence : Yoshiyuki Onno, Department of Preventive Medicine, Nagoya University School of Medicine,

65 Tsurumai-cho Showa-ku Nagoya, 466 Japan.
} 
other research committees on diseases of unknown etiology, specified as intractable diseases, in Japan.

In 1972, the 8 research committees were first founded to study such intractable diseases as SMON, myasthenia gravis, Behcet's disease, multiple sclerosis, systemic lupus erythematosus (SLE), aplastic anemia, sarcoidosis, and fulminant hepatitis/acute necrosis of the liver (the number of research committees had increased to 40 in 1975, and 44 in 1995). In order to investigate epidemiological features of these 8 intractable diseases, the Joint Council on Epidemiological Investigation of the Intractable Diseases was organized in the same year by Dr. Itsuzo Shigematsu (The Institute of Public Health, Tokyo) and Prof. Shun-ichi Yamamoto (University of Tokyo), involving a chairman and one doctor who was in charge of epidemiological studies from each research committee. This Joint Council could now be usually regarded as the origin of the present Research Committee on Epidemiology of Intractable Diseases in Japan.

In 1976, by the financial support from the Ministry of Health and Welfare, the Research Committee on Geopathological and Environmental Scientific Study on Intractable Diseases (Chairman: Prof. Minoru Uematsu, Department of Public Health, Kitasato University School of Medicine) had officially started to study various epidemiological features of intractable diseases in Japan. In 1979, this Committee was named as the Research Committee on Epidemiology of Intractable Diseases, and had lasted until 1981. This Research Committee on Epidemiology of Intractable Diseases was succeeded and chaired by Prof. Kunio Aoki (Department of Preventive Medicine, Nagoya University School of Medicine) from 19821987, and by Prof. Hiroshi Yanagawa (Department of Public Health, Jichi Medical School) from 1988-1992. In the recent three years of 1993-1995, the Research Committee has been chaired by Prof. Yoshiyuki Ohno (Department of Preventive Medicine, Nagoya University School of Medicine).

Over 20 years, an uncountable number of epidemiological papers on intractable diseases have been published mostly in Japanese in each annual progress report, but the papers written in English are also available ${ }^{1-30}$, as listed in the reference section.

The Research Committee, headed by Prof. Y. Ohno, has accomplished some important epidemiological investigations through enthusiastic efforts of the four subcommittees which were coordinated by Drs. Y. Ohno, Tsutomu Hashimoto, Masaki Nagai and Masumi Minowa. In the following sections, some of their scientific accomplishments will be summarized.

\section{DESCRIPTIVE EPIDEMIOLOGICAL STUDIES}

Descriptive epidemiological features of many intractable diseases were mostly disclosed by (1) nationwide epidemiological surveys, (2) the survey, on national scale, of the patients whose medical expenses were subsidized by the Ministry of Health and Welfare in the year 1992, (3) specific analyses of informa- tion routinely available from national mortality statistics, national one-day patient survey, and a computerized database of autopsy records which have been collected from the medical institutions throughout Japan.

A nationwide epidemiological survey has been conducted to obtain the information which would be used for estimating an annual number of patients treated for a given intractable disease in a specified year in Japan and also for clarifying some clinico-epidemiological features of the patients treated. Its epidemiological significance was discussed elsewhere ${ }^{16)}$. Its methodology ${ }^{29)}$ is, in brief, as follows. The subjects to be surveyed were the patients who satisfied the diagnostic/classification criteria defined by each Clinical Research Committee and were treated in a specified year. The targets of the survey were the clinical departments, where the patients were supposed to be treated, in the hospitals which were randomly selected by a stratified sampling method throughout Japan. The sampling rate is about $5 \%, 10 \%, 20 \%, 40 \%, 80 \%, 100 \%$ and $100 \%$ for the stratum of general hospitals with less than 100 beds, 100 199 beds, $200-299$ beds, $300-399$ beds, $400-499$ beds, 500 or more beds and the university hospitals, respectively. In order to increase the survey efficiency, some relevant departments, in which many patients were expected to be treated, were also selected as one of the additional strata. In this nationwide survey, two questionnaires were mailed to the departments randomly selected as above throughout Japan. The first questionnaire aimed simply to inquire a sex-specific number of patients who visited the department and were treated there in a specified year. The second questionnaire aimed to obtain the detailed clinico-epidemiological information on individual patients treated. Based on the reported number of the patients from the departments and the assumption that the response from the department was independent of the reported number, the formulae ${ }^{29)}$ were developed to calculate an estimated annual number of patients treated with its $95 \%$ confidence interval.

Table 1 lists the estimated annual numbers of patients treated for selected intractable diseases, which were disclosed by this nationwide epidemiological survey in 1993-1995.

The survey of the patients, whose medical expenses were subsidized by the Ministry of Health and Welfare in 1992, was conducted in 1993. The patients subsidized for 34 intractable diseases specified by the Ministry were all registered at the administrative office in charge of health services for intractable diseases in all prefectures in Japan. Then, the survey questionnaire was mailed to all offices, requesting to provide the routine demographic and administrative information on each patient. After tremendous computer works on the survey materials collected, a total number of the patients subsidized for 34 intractable diseases in 1992 in Japan was found to be 247,726 (Table 2). Some descriptive epidemiological features of SLE patients subsidized are shown in Figures 1-3, exemplifying the numerous findings obtained by this survey.

A national system for collecting all necessary clinical and epidemiological information, including lifestyle habits and 
Table 1. Estimated annual number of patients treated for selected intractable diseases with $95 \%$ confidence interval

\begin{tabular}{|c|c|c|}
\hline Intractable diseases & Year & No. (95\% Conf.Int.) \\
\hline Fetal hydrocephalus & 1992 & $900(700-1,400)$ \\
\hline Polyarteritis nodosa & 1993 & $1,400(1,400-1,700)$ \\
\hline Wegener's granulomatosis & 1993 & $670(570-780)$ \\
\hline Allergic granulomatous angitis & 1993 & $450(370-530)$ \\
\hline Malignant rheumatoid arthritis & 1993 & $4,200(3,200-5,200)$ \\
\hline Sjögren's syndrome & 1993 & $17,000(15,000-20,000)$ \\
\hline Adult Still's disease & 1993 & $1,300(1,000-1,500)$ \\
\hline Vasculo-Behcet's disease & 1993 & $2,400(2,000-2,800)$ \\
\hline Buerger's disease & 1993 & $10,000(8,400-12,000)$ \\
\hline Inflammatory abdominal aneurysm & 1993 & $920(560-1,300)$ \\
\hline $\begin{array}{l}\text { Ossification of the posterior } \\
\text { longitudinal ligament of the spine }\end{array}$ & 1993 & $16,500(14,000-19,000)$ \\
\hline Senile disciform macular degeneration & 1993 & $14,400(12,100-16,700)$ \\
\hline Sudden deafness & 1993 & $24,000(21,000-27,000)$ \\
\hline Idiopathic bilateral sensorineural hearing loss & 1993 & $700(500-900)$ \\
\hline Mumps deafness & 1993 & $400(300-500)$ \\
\hline Deafness due to immune disorders & 1993 & $200(100-300)$ \\
\hline Psoriasis pustulosa & 1993 & $500(440-560)$ \\
\hline Epidermolysis bullosa hereditaria & 1993 & $330(280-390)$ \\
\hline $\begin{array}{l}\text { Neurofibromatosis I } \\
\text { (von Recklinghausen's disease) }\end{array}$ & 1993 & $6,000(5,400-6,600)$ \\
\hline Neurofibromatosis II & 1993 & $340(270-410)$ \\
\hline Tuberous sclerosis (Bourneville's disease) & 1993 & $2,100(1,800-2,400)$ \\
\hline Moyamoya disease & 1994 & $3,900(3,500-4,400)$ \\
\hline Osteonecrosis of the femoral head & 1994 & $7,900(7,200-8,700)$ \\
\hline IgA nephropathy & 1994 & $24,000(21,000-27,000)$ \\
\hline Polycystic kidney & 1994 & $15,000(13,000-16,000)$ \\
\hline Chronic pancreatitis & 1994 & $32,000 \quad(25,000-39,000)$ \\
\hline
\end{tabular}

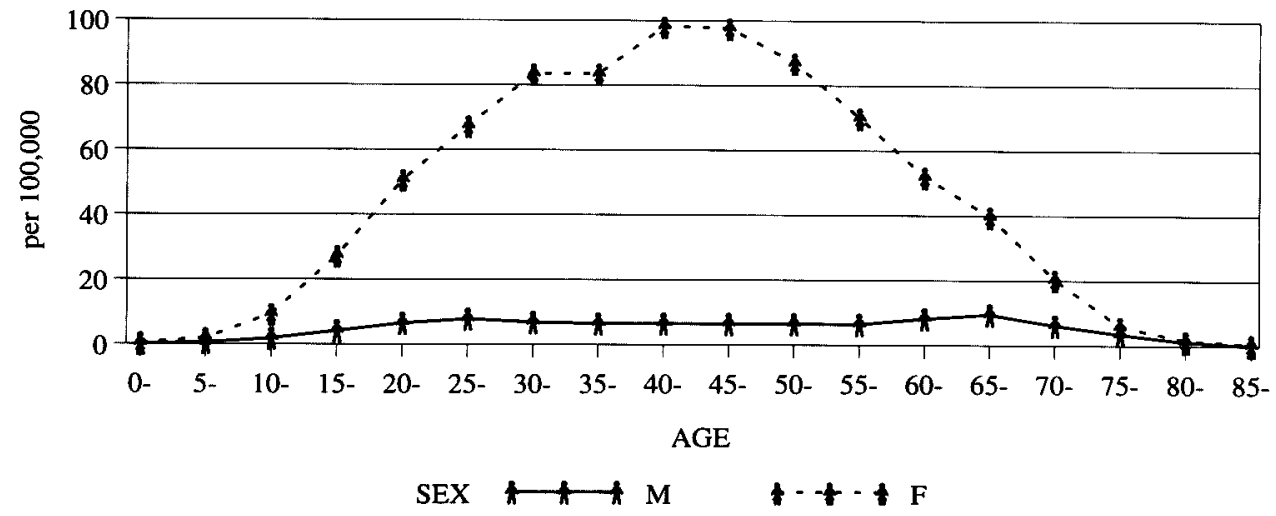

Figure 1. Age and sex-specific number of SLE patients subsidized per 100,000 population in 1992 in Japan

health care needs, from an individual patient to be subsidized will be soon established, since certain members from the Research Committee and the Ministry are now almost at the final stage of its preparation.

Information available from national mortality statistics, national one-day patient survey and a computerized database of autopsy records were routinely and continuously analyzed in the Research Committee, and the findings obtained by these analyses and those by the nationwide epidemiological surveys are to be compiled soon as an English book of descriptive epidemiology of intractable diseases over 15 years in Japan. 


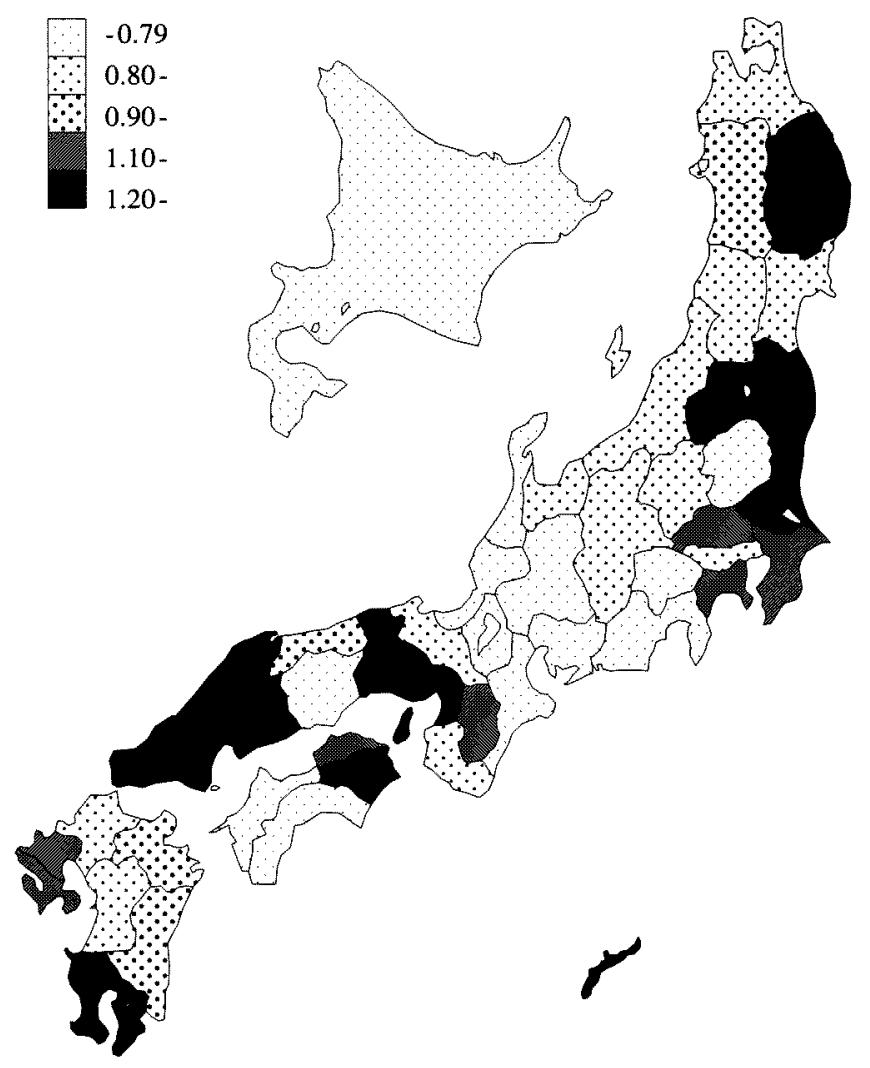

Figure 2. Distribution of the ratio of standardized number of SLE patients newly subsidized in 1992 in Japan (Females)

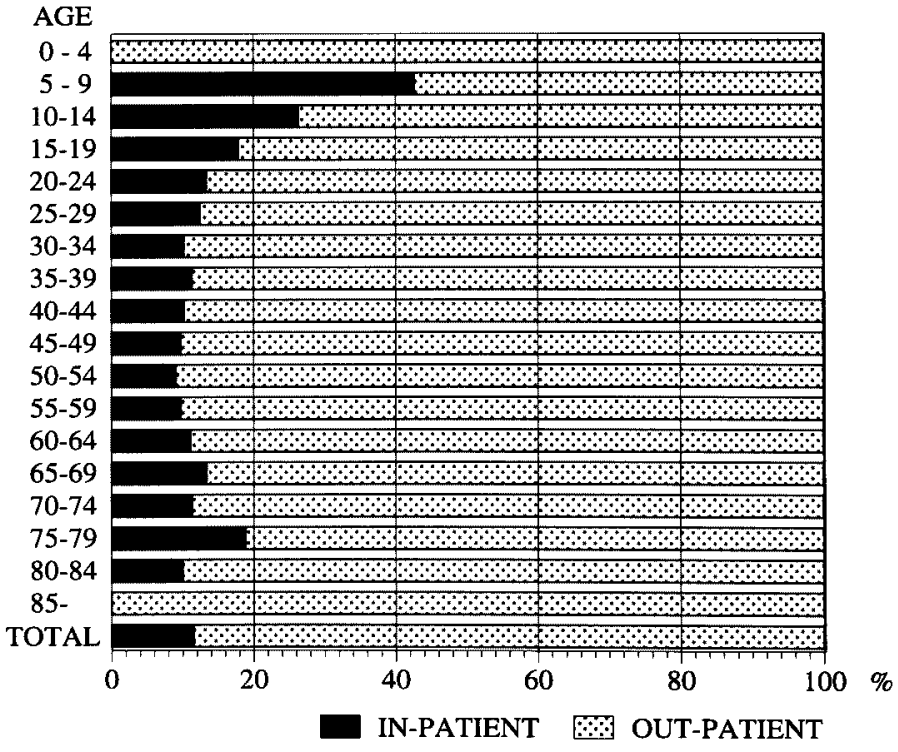

Figure 3. Proportion by age of in/out-SLE patients subsidized in 1992 in Japan (Females) 
Table 2. Numbers of patients subsidized for 34 intractable diseases specified by the Ministry of Health and Welfare of Japan in 1992

\begin{tabular}{|c|c|c|c|c|c|}
\hline \multirow{2}{*}{$\begin{array}{l}\text { Intractable diseases } \\
\text { Behcet's disease }\end{array}$} & \multicolumn{2}{|c|}{ Males } & Females & \multirow{2}{*}{$\frac{\text { Unknown }}{8(-)}$} & \multirow{2}{*}{$\frac{\text { Total }}{13,417(1,189)}$} \\
\hline & $5,640($ & 530) & $7,769(\quad 659)$ & & \\
\hline Multiple sclerosis & $1,324($ & 198) & $2,855(417)$ & $6(1)$ & $4,185($ \\
\hline Myasthenia gravis & $2,517($ & 326) & $5,796(\quad 644)$ & $7(-)$ & $8,320($ \\
\hline Systemic lupus erythematosus & $3,023($ & 438) & $32,652(3,225)$ & $15(3)$ & $35,690(3,666)$ \\
\hline SMON & 454 ( & 13) & $1,556(\quad 52)$ & $2(-)$ & $2,012(\quad 65)$ \\
\hline Aplastic anemia & $3,213($ & 539) & $4,432(\quad 635)$ & $7(2)$ & $7,652(1,176)$ \\
\hline Sarcoidosis & $2,974($ & 626) & $6,772(1,043)$ & $10(5)$ & $9,756(1,676)$ \\
\hline Amyotrophic lateral sclerosis & $1,962($ & 637) & $1,131(379)$ & $1(1)$ & $3,094(1,017)$ \\
\hline $\begin{array}{l}\text { Scleroderma, dermatomyositis, } \\
\text { and polymyositis }\end{array}$ & $3,083($ & 540) & $14,074(1,947)$ & $4(-)$ & $17,161(2,487)$ \\
\hline Idiopathic thrombocytopenic purpura & $5,944($ & $1,475)$ & $13,638(2,597)$ & $12(2)$ & $19,594(4,074)$ \\
\hline Periarteritis nodosa & 666( & 135) & 885( & $-(-)$ & $1,551(283)$ \\
\hline Ulcerative colitis & $14,557($ & $2,825)$ & $15,307(2,535)$ & $18(1)$ & $29,882(5,361)$ \\
\hline Aortitis syndrome & 308( & 25) & $4,110($ & $2(1)$ & $4,420(343)$ \\
\hline Buerger's disease & $8,464($ & 795) & $1,059($ & $3(2)$ & $9,526(912)$ \\
\hline Pemphigus vulgaris & 715( & 106) & $1,187($ & $1(1)$ & $1,903(292)$ \\
\hline Spino-cerebellar degeneration & $5,499($ & $1,075)$ & $5,176(977)$ & $27(8)$ & $10,702(2,060)$ \\
\hline Crohn's disease & $5,990($ & $1,157)$ & $2,908(473)$ & $30(19)$ & $8,928(1,649)$ \\
\hline Fulminant hepatitis & 336( & 201) & $345(181)$ & $-(-)$ & $681(382)$ \\
\hline Malignant rheumatoid arthritis & 942( & 172) & $3,611(482)$ & $2(1)$ & $4,555(655)$ \\
\hline Parkinson's disease & $10,837($ & $2,114)$ & $16,368(2,919)$ & $16(4)$ & $27,221(5,037)$ \\
\hline Amyroidosis & 249( & 64) & 284( & $-(-)$ & $533(138)$ \\
\hline $\begin{array}{l}\text { Ossification of the posterior } \\
\text { longitudinal ligament }\end{array}$ & $6,178($ & $1,378)$ & $3,501(665)$ & $11(3)$ & $9,690(2,046)$ \\
\hline Huntington's chorea & 167( & 29) & 197( & $1(-)$ & 365( \\
\hline Moyamoya disease & $1,561($ & 242) & $2,693(402)$ & $5(1)$ & $4,259(645)$ \\
\hline Wegener's granulomatosis & 198( & 45) & 261( & $-(-)$ & 459( \\
\hline Idiopathic dilated cardiomyopathy & $3,279($ & $801)$ & $1,317(266)$ & $1(-)$ & $4,597(1,067)$ \\
\hline Shy-Drager syndrome & 275( & 100) & 83( & $-(-)$ & $358(123)$ \\
\hline Epidermolysis bullosa & 131( & 15) & 136( & $-(-)$ & 267( \\
\hline Psoriasis pustulosa & 260( & 51) & 294( & $2(1)$ & $556(105)$ \\
\hline Spinal canal stenosis (extensive type) & 332( & 110) & 130( & $1(1)$ & $463(146)$ \\
\hline Primary biliary cirrhosis & 303( & 100) & $2,635(758)$ & $-(-)$ & $2,938(858)$ \\
\hline Severe acute pancreatitis & 351( & 220) & 125( & $1(-)$ & $477(\quad 298)$ \\
\hline $\begin{array}{l}\text { Idiopathic osteonecrosis of } \\
\text { the femoral head }\end{array}$ & $1,490($ & 930) & $597(388)$ & $8(1)$ & $2,095(1,319)$ \\
\hline Mixed connective tissue disease & 29( & 29) & $390(372)$ & $-(-)$ & $419(401)$ \\
\hline Total & $93,251(18$ & $8,041)$ & $154,274(23,131)$ & $201(58)$ & $247,726(41,230)$ \\
\hline
\end{tabular}

Note : The number in parenthesis denotes the number of patients newly subsidized in 1992

\section{ANALYTICAL EPIDEMIOLOGICAL STUDIES}

In order to investigate risk/protective factors for such rare diseases as intractable diseases, a case-control study is the most useful epidemiological study design. When conducting this type of study, however, how to obtain controls is the most crucial issue.

In the Research Committee, it was decided to be a main purpose to explore systematically the associations of fundamental lifestyle habits with selected intractable diseases by case-control studies, which would use so-called "pooled controls". This controls were collected as a reference of healthy Japanese pop- ulation aged 20 to 79 years, and successfully provided by the members of the Research Committee, who have been for many years conducting annual medical and health check-ups of the inhabitants in 19 areas throughout Japan and of the employees of 4 private enterprises. Finally, the pooled controls consisted of 73,861 healthy subjects $(35,016$ males and 38,845 females) aged 20-79.

While establishing the controls, eligible patients as cases had been collected in good cooperation of 10 Clinical Research Committee on Intractable Diseases. Intractable diseases analyzed by our case-control study (numbers of the patients finally collected) were as follows : mixed connective tissue disease 
Table 3. Odds ratios by smoking and drinking habits

\begin{tabular}{|c|c|c|c|}
\hline Diseases/smoking habits & Never & Quitted & Currently \\
\hline Mixed connective tissue disease & 1.00 & 1.35 & 1.03 \\
\hline Idiopathic dilated cardiomyopathy & 1.00 & 2.13 & $2.91^{*}$ \\
\hline Idiopathic interstitial pneumofibrosis & 1.00 & 1.18 & $2.30^{*}$ \\
\hline Ulcerative colitis & 1.00 & 0.41 & $0.11 *$ \\
\hline von Recklinghausen's disease & 1.00 & 0.13 & $0.30^{*}$ \\
\hline Systemic sclerosis & 1.00 & 0.00 & 1.10 \\
\hline Psoriasis pustulosa & 1.00 & 0.00 & $3.57^{*}$ \\
\hline Sudden deafness & 1.00 & 1.38 & $2.11^{*}$ \\
\hline Behcet's disease & 1.00 & 2.12 & $2.20^{*}$ \\
\hline Osteonecrosis of the femoral head & 1.00 & 1.97 & $5.48^{*}$ \\
\hline $\begin{array}{l}\text { Ossification of the posterior } \\
\text { longitudinal ligament of the spine }\end{array}$ & 1.00 & 1.06 & 0.75 \\
\hline Diseases/drinking habits & Never & Quitted & Currently \\
\hline Mixed connective tissue disease & 1.00 & 0.00 & 1.47 \\
\hline Idiopathic dilated cardiomyopathy & 1.00 & 0.48 & 1.61 \\
\hline Idiopathic interstitial pneumofibrosis & 1.00 & 0.45 & 0.71 \\
\hline Ulcerative colitis & 1.00 & 0.57 & $0.29 *$ \\
\hline von Recklinghausen's disease & 1.00 & 0.76 & 1.67 \\
\hline Systemic sclerosis & 1.00 & 0.44 & 0.49 \\
\hline Psoriasis pustulosa & 1.00 & 0.00 & $0.30^{*}$ \\
\hline Sudden deafness & 1.00 & 0.69 & 0.80 \\
\hline Behcet's disease & 1.00 & 1.22 & 0.68 \\
\hline Osteonecrosis of the femoral head & 1.00 & $3.15^{*}$ & $3.42 *$ \\
\hline $\begin{array}{l}\text { Ossification of the posterior } \\
\text { longitudinal ligament of the spine }\end{array}$ & 1.00 & 0.59 & 0.78 \\
\hline
\end{tabular}

*: $95 \%$ confidence interval does not include 1.00 , i.e., significant odds ratio

$(\mathrm{n}=120)$, idiopathic dilated cardiomyopathy $(\mathrm{n}=108)$, idiopathic interstitial pneumofibrosis $(n=164)$, ulcerative colitis $(n=104)$, von Recklinghausen disease ( $n=55$ ), progressive systemic sclerosis $(n=94)$, psoriasis pustulosa $(n=60)$, ossification of the posterior longitudinal ligament $(n=216)$, idiopathic osteonecrosis of the femoral head $(n=116)$, sudden deafness $(n=144)$, and Behçet's disease $(n=923)$.

Information, which were collected by a self-administered questionnaire, included such basic lifestyle habits as smoking and drinking, sleep duration in hours, physical activities, usual dietary practices, and reproductive information in females. Conditional logistic regression analyses were adopted to analyze information, matching each case to all available controls for age, sex and area. Disease-specific associations with smoking and drinking habits are selectively shown in Table 3 by odds ratio with its significance.

Besides these 11 case-control studies which have used "pooled controls", two case-control studies by traditional methodology were carried out for scleroderma and idiopathic osteonecrosis of the femoral head among SLE patients. Risk factors significantly incriminated by the former case-control study were lower body mass index, mother's history of cancer, Raynaud-like symptom in family members, use of vibration tools for 4 years or more, and experience of spontaneous abor- tion in females. The latter case-control study disclosed such risk factors of developing idiopathic osteonecrosis of the femoral head among SLE patients as Raynaud's phenomenon at onset and lupus nephritis at diagnosis of SLE, and such clinical signs and symptoms during SLE patient as epicarditis, hypertension, psychoneurological disorders, and renal dysfunction.

\section{OTHER EPIDEMIOLOGICAL STUDIES}

A series of studies on quality of life (QOL) among the patients with intractable diseases was one of the main other epidemiological studies, which are still underway in the Research Committee. They included the investigations of developing the scales of measuring QOL, which are common and specific to the patients with intractable diseases. After vigorous discussions and debates among the members of the Research Committee, 66 basic questions, which will be used to develop the final scale of measuring common QOL to all patients with intractable diseases, were finally proposed. In contrast, two scales of measuring QOL, which is specific to each intractable disease, were also successfully developed ; one for the patients with neurological intractable diseases and one for those with idiopathic disorders of haematopoietic sys- 
tem, and will be actually used to measure their QOL next year.

Besides these studies for measuring QOL, the determinants of QOL itself were also studied, simplifying QOL as life satisfaction. The determinant studies were conducted for Behcet's disease, idiopathic interstitial pneumofibrosis, pigmentary degeneration of the retina, SLE, and Parkinson's disease. Not only physical conditions and activity level of daily life, but also such factors as jobs, socio-environmental conditions, human relations, and hobbies were found as important QOL determinants.

The follow-up studies to detect clinical prognostic determinants were also planned and executed for ossification of the spinal ligaments, Budd-Chiari syndrome, sarcoidosis, autoimmune hepatitis, and primary biliary cirrhosis. The studies could disclose the disease-specific determinants for clinical prognosis.

Epidemiological-pathological studies, which utilized a computerized database of all autopsy records from 1972 in Japan, explored such important aspects of autopsy series with intractable diseases as the frequencies of intractable diseases complicated each other among 30 different intractable diseases, the secular trends in autopsy findings and causes of death among SLE patients, the frequencies of non-advanced cancer complicated among autopsy cases with intractable diseases, the concordance rates of clinical and autopsy diagnosis in amyloidosis, the 20 years-trends in clinical and pathological diagnosis among such autopsy cases as sarcoidosis, polyarteritis nodosa, and Sjögren's syndrome.

Longitudinal follow-up studies of the patients who have been subsidized for 8 to 25 years were also undertaken to examine the rate of new/re-entry to the governmental subsidiary system, that of continued/dis-continued subsidization, and their clinical prognosis with certified causes of death as well.

Finally, the scientific activities and their findings, which were exemplified above, have been reported in Japanese in three volumes of "Annual Progress Report of the Research Committee on Intractable Diseases : 1993, 1994 and 1995”. But hoped in this communication is that foreign readers, in particular, could be acquainted with the recent research activities by the Research Committee and possibly seek for international collaborations with us in epidemiological studies on intractable diseases.

\section{ACKNOWLEDGEMENTS}

The authors are most grateful to an uncountable number of doctors and administrative officers throughout Japan, who supported the scientific activities of the Research Committee on Epidemiology of Intractable Diseases, to the scientists of the Committee who were not named as the authors, and to those of the other 43 Research Committees on Intractable Diseases.

The scientific works described in this communication were largely supported by Grants-in-Aid from the Ministry of Health and Welfare of Japan.

\section{REFERENCES}

1. Aoki K, Shimizu H. Epidemiology of leukemia and aplastic anemia. Natl Cancer Inst Monogr, 1977 ; 47 : 23-30.

2. Aoki K, Ohno Y, Shimizu H, Kuroishi T, Ohtani M. Epidemiology of the diseases of blood and hematopoietic system. Jpn J Med, 1977 ; 16 : 329-341.

3. Aoki K, Ohtani M. A community study on S.M.O.N. in Nagoya. In ; Gent M, Shigematsu I, eds. Epidemiology Issues in Reported Drug-Induced Illness S.M.O.N. and Other Examples, McMaster University Library Press, Hamilton, Ontario, Canada, 1978 : 224-237.

4. Shimizu H, Kuroishi T, Tominaga S, et al. Production amount of chrolamphenicol and mortality rate of aplastic anemia in Japan. Acta Haematol Jpn, 1979 ; 42 : 689696.

5. Aoki K, Fujiki N, Shimizu H, Ohno Y. Geographic and ethnic differences of aplastic anemia in humans. In ; Najean Y, ed. Medullary Aplasia, Masson Publishing Inc, New York, 1980 : 79-88.

6. Okada H, Ohno Y, Aoki K, Kuroishi T. Trend in prescription rates of drugs suspected to induce haematopoietic disorders in a population in Nagoya. Nagoya $\mathbf{J}$ Med Sci, $1980 ; 43$ : 29-39.

7. Aoki K, Sasaki R, Mizuno S, Ohno Y. Epidemiological aspects of aplastic anemia. Acta Haematol Jpn, $1981 ; 44$ : 1288-1297.

8. Mizuno S, Aoki K, Ohno Y, Sasaki R, Hamajima N. Time series analysis of age-specific death rates from aplastic anemia and the trend in production amount of chloramphenicol. Nagoya J Med Sci, 1982 ; 44 : 103115.

9. Ohno Y, Hamajima N, Sasaki R, Aoki K. Epidemiological features of intractable diseases : Variations in death by sex and age. Nagoya J Med Sci, 1983 ; 45 : $79-87$.

10. Okada H, Aoki K, Ohno Y, Kitazawa S, Ohtani M. Effects of metal- containing drugs taken simultaneously with clioquinol upon clinical features of SMON. J Toxicol Sci, 1984 ; 9 : 327-341.

11. Aoki K, Hosoda $Y$, Yanagawa $H$, et al., eds. Epidemiology of Intractable Diseases in Japan. The Epidemiology of Intractable Diseases Research Committee, The Ministry of Health and Welfare of Japan, Department of Preventive Medicine, Nagoya University School of Medicine, Nagoya, 1986.

12. Agata T, Nakae K, Maeda K, Aoki K, Mizushima $Y$. The epidemiological features and trends of Behcet's disease in Japan from 1972 to 1985 . Lehner T, Barnes CG, eds. International Congress and Symposium Series 103Recent advances in Behcet's disease. Royal Society of Medicine Services, London, New York, 1986 : 187-198.

13. Kurihara M, Aoki K, eds. Mortality Statistics of Intractable Diseases in Selected Countries. Epidemiology 
of Intractable Disease Research Committee, The Ministry of Health and Welfare of Japan, Nagoya, 1988.

14. Hamajima N, Sasaki R, Aoki K, Shibata A. A notable change in mortality of aplastic anemia observed during the 1970's in Japan. Blood, $1988 ; 72$ : 995-999.

15. Yamaguchi $M$, Hosoda $Y$, Sasaki R, Aoki K. Epidemiological study on sarcoidosis in Japan : Recent trends in incidence and prevalence rates and changes in epidemiological features. Sarcoidosis, $1989 ; 6: 138$ 146.

16. Yanagawa $H$, Sasaki $R$, Nagai $M$, et al., eds. Recent Progress of Epidemiology of Intractable Diseases in Japan. The Epidemiology of Intractable Diseases Research Committee, The Ministry of Health and Welfare of Japan, 1992.

17. Yanagawa H, Nagai M, Fujita Y. Epidemiological overview of intractable diseases in Japan. J Epidemiol, 1992 ; 2 : S189-S195.

18. Tamakoshi A, Sasaki R, Hamajima N, et al. A nationwide survey of congenital hydrocephalus in JapanEstimated prevalence and incidence. Europ J Public Health, $1991 ; 1: 86-89$.

19. Hirota Y, Hirohata T, Fukuda K, et al. Association of alcohol intake, cigarette smoking, and occupational status with the risk of idiopathic osteonecrosis of the femoral head. Am J Epidemiol, 1992 ; 157 : 530-538.

20. Shibasaki H, Kubo N, Nishitani H, et al. Nationwide survey of multiple sclerosis in Japan : reappraisal of clinical features. J Trop Geogr Neurology, $1992 ; 2$ : 73-82.

21. Hashimoto $S$, Fukutomi K, Nagai $M$, et al. Response bias in nationwide epidemiological survey of an intractable disease in Japan. J Epidemiol, 1991 ; 1 : 27-30.
22. Yanagita N, Nakashima T, Ohno Y, et al. Estimated annual number of patients treated for sensorineural hearing loss in Japan. Acta Otolaryngol, 1994 ; Suppl 514 : 9-13.

23. Nakashima T, Yanagita N, Ohno Y, et al. Comparative study of sudden deafness by two nationwide epidemiological surveys in Japan. Acta Otolaryngol, 1994 ; Suppl $514: 14-16$.

24. Nakadaira H, Endoh $K$, Yamamoto $M$, et al. A case-control study of Buerger's Disease. J Epidemiol, 1991 ; 1 : 19-25.

25. Nagai M, Hirohata $T$, Matsumoto $Y$, et al. A case-control study of female systemic lupus erythematosus in Japan. Europ J Public Health, 1993 ; 3 : 172-176.

26. Nakamura Y, Labarthe DR. A case-control study of ulcerative colitis with relation to smoking habits and alcohol consumption in Japan. Am J Epidemiol, 1994 ; 140 : 902-911.

27. Nakamura $\mathbf{Y}$, Kobayashi M, Nagai M, et al. A case-control study of ulcerative colitis in Japan. J Clin Gastroenterol, $1994 ; 18$ : 72-79.

28. Nakamura $Y$, Ohshiro H, Nose T, et al. A case-control study of ossification of the posterior longitudinal ligament of the spine in Japan. J Epidemiol, 1995 ; 5: 29-33.

29. Wakai K, Tamakoshi A, Ohno Y, et al. Estimated prevalence of Sjögren's syndrome in Japan : Findings from a nationwide epidemiological survey. J Epidemiol, 1995 ; $5: 125-129$.

30. Nagata C, Fujita S, Iwata H, et al. Systemic lupus erythematosus : A case-control epidemiologic study in Japan. Int J Dermatol, 1995 ; 34 : 333-337. 